\title{
Physical rehabilitation to treat neuropathic pain
}

\author{
Reabilitação física no tratamento de dor neuropática \\ Juliana Barcellos de Souza', Cristiane Lima Carqueja², Abrahão Fontes Baptista ${ }^{3,4}$
}

DOI 10.5935/1806-0013.20160056

\section{ABSTRACT}

BACKGROUND AND OBJECTIVES: Neuropathic pain is disabling, decreases quality of life, impairs professional performance, and limits social participation of patients living with excruciating pain. In this context, it is easy to see physical rehabilitation as facilitator of autonomy and mobility. However, therapeutic action goes beyond these actions. With technological advances, new approaches are proposed and it now it is possible to measure the performance of physical methods for pain modulation.

CONTENTS: The innovative potential of physical rehabilitation to treat neuropathic pain is discussed. Reflections are made on therapeutic options such as: electrothermotherapy, manual therapy, physical exercise, transcranial stimulation with constant current, repetitive transcranial magnetic stimulation, visual mental exercises and mirror therapy, among others. Therapeutic modalities shall be addressed according to some neuropathic pain conditions, so the authors propose a parallel between specific pathologic mechanism of some neuropathic pain conditions and the neurophysiologic mechanism of the proposed therapeutic modality. CONCLUSION: In spite of different pathological mechanisms and different ways of physical and mental approach with patients, the importance of active participation of patients during the rehabilitation process has to be stressed.

Keywords: Clinical practice update, Evidences, Neuropathic pain, Rehabilitation.

\section{RESUMO}

JUSTIFICATIVA E OBJETIVOS: Dores neuropáticas são incapacitantes, reduzem a qualidade de vida, prejudicam a atuaçáo profissional, limitam a participaçáo social dos pacientes que convivem com dores lancinantes. Neste contexto visualiza-se rapidamente a reabilitação física como facilitador de autonomia e mobilidade. Contudo, a ação terapêutica estende-se além destas. Com avanços tecnológicos, novas abordagens são propostas e tornou-se possível mensurar a atuaçáo de métodos físicos na modulaçáo da dor.

CONTEÚDO: Discute-se o potencial inovador da reabilitação física no tratamento das dores neuropáticas. Reflexóes sobre opçóes terapêuticas como, por exemplo: eletrotermoterapia, terapia manual, exercício físico, estimulaçăo transcraniana com corrente constante, estimulação magnética transcraniana repetitiva, exercícios mentais visuais, terapia do espelho entre outros. As modalidades terapêuticas serão abordadas de acordo com algumas condiçôes de dor neuropática, desta forma os autores propóem um paralelo entre o mecanismo patológico específico de algumas condiçôes de dor neuropática e o mecanismo neurofisiológico da modalidade terapêutica proposta.

CONCLUSÁO: Embora mecanismos patológicos diferentes e várias vias de abordagem física e mental com os pacientes, destaca-se a importância da participação ativa do paciente durante o processo de reabilitação.

Descritores: Atualização para prática clínica, Dor neuropática, Evidências, Reabilitação.

1. Universidade Federal de Santa Catarina, Hospital Universitário, Serviço de Fisioterapia, Florianópolis, SC, Brasil.

2. Centro Catarinense de Reabilitaçáo, Medicina Física e Reabilitação, Florianópolis SC, Brasil.

3. Universidade Federal da Bahia, Instituto de Ciências da Saúde, Laboratório de Eletroestimulação Funcional, Salvador, BA, Brasil.

4. Universidade Federal da Bahia, Faculdade de Medicina, Programa de Pós-Graduação em Medicina e Saúde, Salvador, BA, Brasil.

Conflict of interests: none - Sponsoring sources: none.

Correspondence to:

Juliana Barcellos de Souza

Rua Dep Antonio Edu Vieira, 58

Clinica Educa a Dor

88040-000 Florianópolis, SC, Brasil.

E-mail: juliana.barcellos@ufsc.br

(c) Sociedade Brasileira para o Estudo da Dor

\section{INTRODUCTION}

Neuropathic pain (NP) is a complex and heterogeneous condition with negative impact on physical, mental and professional quality of life, associated to high healthcare costs ${ }^{1}$. Described by the International Association for the Study of Pain (2011) in terms of injury or disease affecting peripheral or central somatosensory nervous system, NP affects $1 \%$ to $5 \%$ of world population. Part of its complexity is due to heterogeneous clinical manifestations with oscillates between constant or intermittent, spontaneous or induced pain, described by words such as shooting, stabbing, electric shock, burning, painful tingling, pressing, itching and pricking. This pathological condition is present in trigeminal neuralgia (TN), radicular NP and thalamic pain. This pain is associated to other clinical conditions, such as diabetic peripheral neuropathy affecting $46 \%$ of diabetes mellitus (DM) patients ${ }^{2}$; postherpetic neuralgia affecting $10 \%$ of patients 3 months after acute herpes-zoster ${ }^{3}$; chronic postoperative pain which may affect $53 \%$ of patients one year after laminectomy ${ }^{4}$; post-cancer NP, such as chemotherapy-induced neuropathy, or neuropathy secondary to tumor antigens, or by neural structures compression; post-stroke $(S)$ neuropathies; and post-spinal cord injury NP affecting $31 \%$ of patients ${ }^{5}$. In addition, there are some special cases such as complex regional pain syndrome (CRPS), nervous compression syndrome after burn injuries and phantom limb pain.

NP is difficult to handle and is associated to patients' dissatisfaction with surgical, pharmacological and non-pharmacological treatments. Several best practices guidelines are proposed to standardize treatments, multiprofessional approaches and to promote better pain management in this population. However, in evaluating treatment models of such guidelines one can see how recent the use of physical rehabilitation is as adjuvant for NP treatment. In summary, documents directed to neuropathic pain in general are almost exclusively concentrated in the pharmacological approach ${ }^{6,7}$ or just mention the participation of physical and mental health professionals, without determining their functions or objectives ${ }^{8}$. Physiotherapy and occupational therapy are addressed in the guidelines to treat post-spinal cord injury neuropathic pain ${ }^{9}$, with broad discussion on physical rehabilitation of this NP sub-population.

Within this context, this article discusses the innovative potential of physical rehabilitation to treat neuropathic pain. There are several therapeutic options, such as electrothermotherapy, manual therapy with muscle energy techniques, mobilization without thrust and manipulation; cold therapy and traction, therapeutic massage, drug and cervical collar, physical strengthening exercise, stretching and aerobic training, constant current transcranial stimulation (CCTS), repetitive transcranial magnetic stimulation (rTMS), visual mental exercises, imagery, mirror therapy, somatonsensy rehabilitation. With neurophysiologic support, some modalities were largely studied, such as physical exercises, and have shown high scientific evidence of their therapeutic effects; however more recent ones, such as mirror therapy have shown low scientific evidence. Therapeutic approaches shall be addressed according to some NP conditions, so authors propose a parallel between specific pathologic mechanisms of some NP conditions and the neurophysiologic mechanism of the proposed therapeutic modality. Physical rehabilitation shall be discussed in the following clinical conditions: diabetic neuropathy, central nervous system (CNS) injuries, radiculopathy and peripheral nerves entrapment syndromes, special cases such as burn injuries, phantom limb pain and CRPS.

\section{PHYSICAL REHABILITATION IN DIABETIC NEUROPATHY}

Most prevalent NP symptom is associated to DM and affects approximately $46 \%$ of patients ${ }^{2}$. Systemic changes of this metabolic disease affect vascular and nervous tissues enabling the installation of distal symmetric sensory motor polyneuropathy, also described as diabetic neuropathy. There are some 
hypotheses for the pathophysiological mechanism to justify symmetric degeneration of sensory A-delta fibers and C fibers during periods of hyperglycemia and poor glycemic control ${ }^{10}$. Hyperglycemia is considered a vector speeding up the formation of advanced glycation end products (AGEs) in peripheral nerves and adjacent tissues, facilitating carbonyl and oxidative stress. These biochemical and metabolic changes induce morpho-functional changes such as (a) increased inflammatory mediators expression in myelinated or demyelinated neurons and Schwann cells and (b) functional changes in microvascular beds ${ }^{10,11}$. Progressive evolution of peripheral DM neuropathy impairs, among others, plantar sensitivity and skin injuries healing, requiring from patients excessive care with the health of their feet, otherwise this will lead patients from injury to necrosis and infection of skin and underlying tissues, the treatment of which is amputation of the injured segment.

It was erroneously estimated that diabetic neuropathy was a protective factor to phantom limb sensation and pain after amputation. However, the prevalence of phantom pain complaints in lower limb is not different between diabetics with peripheral neuropathy ( $82 \%$ of cases) and non diabetics $(89 \% \text { of cases })^{12}$. Therapeutic modalities to treat diabetic neuropathy vary from prescription of exercises to prevent the disease to the use of technological advances such as rTMS and CCTS to promote cortical changes in such pain modulation.

In general, exercise routines are major adjuvants associated to medical and pharmacological treatment for peripheral neuropathy. There are evidences of benefits such as (a) functional increase in macro and microvascular beds, (b) improved endothelial function, (c) decreased vasoconstriction and increased blood flow, (d) increased muscle strength, (e) increased cardio-respiratory resistance, (e) direct increase of glycemia levels and formation of products such as AGEs and (f) decreased DM-associated comorbidities, such as systemic hypertension and atherosclerosis ${ }^{10}$.

In comparing aerobic exercises versus strengthening, a systematic review and meta-analysis has observed that the former tends to further decrease glycosylated hemoglobin as compared to the latter ${ }^{13}$. Although vast literature showing beneficial effects of physical exercises on diabetic neuropathy, there are few studies with outcome on pain intensity. Three important studies have investigated the effect of physical exercises on diabetic neuropathy pain intensity. With aerobic and resisted training during 10 weeks with 17 diabetic neuropathy patients, Kluding et al. ${ }^{14}$ have shown significant decrease in pain intensity measured by the visual analog scale (VAS) and decreased neuropathic symptoms, in addition to increased intraepidermal nervous fibers by skin biopsy.

In spite of methodological limitations (e.g., small sample and lack of control group) this was one of the first studies to describe improved neuropathic symptoms and changes in skin nervous fibers after a program of exercises with NP diabetic patients ${ }^{16}$. Another aerobic exercise program lasting 16 weeks ( $\mathrm{n}=14$ patients) has shown significant improvement in decreasing general pain interference (walking, working, social relationship and sleep), however without changing pain intensity ${ }^{15}$.

In line with these findings, a qualitative focus group study with $47 \mathrm{NP}$ patients stresses the biopsychosocial complexity of their complaints, especially loss of functional capacity (walking, standing up, balance, orthostatism, mobility), decreased daily productivity (leisure activities, work), psychosocial consequences (anxiety, irritability, fear) and disorders (insomnia, non-restorative/regenerator sleep) ${ }^{16}$. Data such as these are consistent with reflections of studies with other chronic pain populations, where the pain relief objective does not overcome that of quality of life, quality of sleep and less interference of pain in daily life ${ }^{17}$.

Among adverse effects of aerobic exercises in NP diabetic population, there is fatigue, however pain outcome is still poorly explored by protocols applied to this population ${ }^{18}$. Fatigue is also reported by non-diabetic patients after intense aerobic exercises.

In looking for new alternatives for diabetic NP, two studies have evaluated the efficacy of the association of exercises in vibratory platforms to treat diabetic $\mathrm{NP}^{19,20}$. Studies with small sample sizes ( $\mathrm{n}=8$ and 10 , respectively) and with low scientific evidence have shown significant decrease in pain intensity by the visual analog and NP scales ${ }^{19}$ and improvement in strength and balance parameters ${ }^{20}$.

Although some advocate the use of this equipment for NP physical rehabilitation, its physiological effect and improvement of biomechanical variables are still questionable.

Electrotherapy has been described as physical therapy method with potential analgesic effect on NP, especially diabetic neuropathic pain. Studies have shown transcutaneous electrical nerve stimulation (TENS) as preferential method $^{21}$. In a meta-analysis ${ }^{22}$, TENS to treat diabetic neuropathy had medium-term beneficial effects ( 6 and 12 weeks) in pain relief. TENS therapy was well tolerated and there have been no reports of adverse effects.

Included studies used low frequency TENS $(2-4 \mathrm{~Hz})$, but analgesic effects of different parameters were not analyzed. So, TENS may be effective to handle peripheral NP, but randomized, double-blind studies comparing parameters are still needed. Possible action mechanisms of electrotherapy would be related to local release of neurotransmitters, such as serotonin, adenosine triphosphate (ATP) and endorphins.

Low frequency currents improve microcirculation and endoneural blood flow, which might be particularly interesting for diabetic neuropathy. Studies suggest that TENS activates analgesia-producing central mechanisms. There are evidences that low frequency TENS activates $\mu$ opioids in spinal cord and brainstem, and high frequency currents would produce effect by means of $\delta$ receptors ${ }^{21}$. Mima et al..$^{23}$ have observed that high frequency TENS also decreases motor evoked potential amplitude, suggesting a decrease in corticospinal and motor cortex excitability.

Primary motor cortex (M1) modulation to control pain may also be obtained by noninvasive transcranial neuromodulation ${ }^{24}$. Most commonly used resources are rTMS and CCTS. Primary motor cortex excitatory modulation may be obtained with high frequency rTMS (in general above $5 \mathrm{~Hz}$ ) or anodal CCTS (anode in M1 and cathode in contralateral supraorbital region).

Stimulation of these areas modulates thalamus and a series of other regions related to neural networks of brain pain processing, including sensory and emotional processing regions ${ }^{25,26}$. Kim et al. ${ }^{27}$ have carried out a clinical trial with $60 \mathrm{NP}$ patients divided in three groups submitted to active anodal CCTS in M1, in dorsolateral pre-frontal cortex (DLPFC) or simulated CCTS, for five consecutive days. Only M1 modulation was able to significantly decrease pain and the effect was maintained for up to four weeks after treatment.

Similar result was found in patients with diabetic neuropathy and associated plantar fasciitis. After five days of anodal CCTS, patient had clinically important reduction of heel pain, associated to opioid withdrawal ${ }^{28}$. To date, just one study has investigated rTMS to specifically treat diabetic neuropathy patients' pain. Onesti et al. ${ }^{29}$ used deep stimulation coil (H-coil), in five treatment sessions. Results were pain decrease associated to decrease of a physiological pain marker, the $\mathrm{H}$ reflex.

In summary, physical rehabilitation in diabetic peripheral neuropathy involves: (a) aerobic exercises due to their neurovascular benefits, more than strengthening exercises, (b) TENS and (c) rTMS. However, treatment protocols, parameters, intensity, time and duration and, especially studies with outcomes on pain are necessary to improve understanding and prescription of such modalities.

\section{PHYSICAL REHABILITATION FOR NEUROPATHIC PAIN AFTER CENTRAL NERVOUS SYSTEM INJURIES}

Injuries or dysfunctions affecting the CNS may induce difficult to control pain, known as central pain. Most common causes are traumatic spinal cord injuries or diseases coursing with myelopathy, brain injuries, especially those involving the thalamus, multiple sclerosis and CNS tumors. In such conditions, injuries may be themselves the source of symptoms. It is also possible that endogenous inhibitory mechanisms are affected, generating pain by inhibitory failure.

In all these situations, patients shall have different NP presentations and physical treatment is part of the list of therapeutic possibilities. Depending on the case, it will be possible to interfere with dysfunctional mechanisms with techniques stimulating endogenous pain inhibition such as neuromodulation with electric or magnetic transcranial or peripheral stimulation, acupuncture, exercises and mental practices. Next, a specific approach for each possibility where there are evidences of clinical use shall be described.

Noninvasive transcranial neuromodulation with transcranial electric stimulation with direct current was initially clinically observed in patients with pain secondary to spinal cord injury. Fregni et al..$^{30}$ have shown that five days of anodal CCTS in M1 decreases patients' pain without interfering with the neuropsychological condition or being associated to the presence of anxiety and depression.

Two recent meta-analyses have shown that anodal CCTS in M1 has moderate analgesic effect on spinal cord injury pain ${ }^{31,32}$. The review of Boldt et al..$^{31}$ has also involved other noninvasive neuromodulatory resources such as rTMS and acupuncture, which however have not shown effect on these patients' pain. 
CCTS was studied as a way to control multiple sclerosis pain in $2010^{33}$. This study has shown that five consecutive days of anodal CCTS in M1 were able to decrease pain and improve quality of life of multiple sclerosis patients. No subsequent study has directly addressed pain in these patients, but rather fatigue and psychiatric disorders.

High frequency rTMS is the most common modality to control pain. In case of spinal cord injury, this modality has shown controversial effects for pain control. Ylmaz et al. ${ }^{34}$ have shown significant pain decrease in these patients, however statistical analysis used in this study has not compared interaction between group and time. Both hand and lower limb stimulation seem to have better effect as compared to simulated stimulation ${ }^{35}$, however this was not shown in an initial study ${ }^{36}$.

An important factor might be the number of administered pulses, since studies with around 500 to 1000 pulses by session have not shown analgesic effect $^{36,37}$. Low frequency TENS, another electrical stimulation modality, however for peripheral nerves, may also have analgesic effect ${ }^{38,39}$.

Exercises were studied in some clinical trials as ways to control pain in spinal cord injury patients. A systematic review with meta-analysi ${ }^{31}$ has shown that this physical intervention modality had the best effect on pain decrease, among a series of non-pharmacological interventions involving neuromodulation, acupuncture, TENS, self-hypnosis and cognitive behavioral therapy.

\section{PHYSICAL REHABILITATION IN RADICULOPATHIES AND PERI- PHERAL NERVE ENTRAPMENT SYNDROMES}

Nervous compression is an underlying cause of some neuropathic pains. Several anatomic areas are described as being more vulnerable to vasculo-nervous compression, such as: osteofibrous channels of the distal pathway of brachial plexus nerves (e.g., carpal tunnel), lumbar plexus (sciatic pain) or in the entrance of trigeminal nerve root in the cerebellopontine cistern. Compressive neuropathies have a central component, in addition to a biomechanical cause by compression. Among neuropathic pains involving compression components there are: trigeminal neuralgia, radicular NP and NP in burned patients.

Trigeminal neuralgia is an excruciating, allodynia pain with high intensity. Vascular compression of trigeminal nerve dorsal root may be caused by superior cerebellar artery, by intracranial vascular abnormality, internal carotid artery aneurysm, as well as by tumors, foreign body, bone injuries or osteotomas. Although these results justify trigeminal paroxysmal pain, some studies describe excruciating facial pain without compression, as well as there are reports of compression without facial pain ${ }^{40}$.

So, the bioresonance theory is proposed ${ }^{41}$ where changes in vibration frequency of structures adjacent to the trigeminal nerve resound and may induce nervous fibers injury, change impulse transmission and finally result in facial pain. Other findings include nervous root demyelination, as in the case of multiple sclerosis ${ }^{42}$. Other trigeminal neuralgia causes would be trauma, viral infection such as postherpetic neuralgia, and genetic causes ${ }^{40}$. Most prevalent surgical approach would be Gamma Knife surgery, microvascular $^{43}$ or radiofrequency ${ }^{40}$ decompression. Studies describing the effects of conservative non-pharmacological treatments are few, so they have still low scientific evidence.

Physiotherapy, occupational therapy and other therapeutic approaches acting by movement, as well as using electric and thermal stimuli, tend to promote physical function improvement and functionality gain. The success of combining these therapeutic approaches with drug therapy would be indicated in early pain stages, within a multimodal context, although some patients benefit from this functional approach to treat pain ${ }^{44}$. Burst TENS during 20 to 40 days on the affected nerve, with evaluation after one and three months, has shown significant decrease in pain intensity evaluated by VAS, without report of adverse effects ${ }^{45}$.

Similar effects are identified when applying TENS in refractory trigeminal neuralgia or with partial response to drugs, with slightly better effect of the constant current as compared to burst mode ${ }^{46}$. Although results of these studies are beneficial, both have some methodological limitations which weaken the effect for generalization of results. Hagenaker et al. ${ }^{47}$. have shown that anodal CCTS in M1, 20 minutes per day for 14 days, decreases pain of trigeminal neuralgia patients in $18 \%$, result with low clinical effect.

As opposed to trigeminal neuralgias, cervical and lumbar radiculopathies have better prognosis with conservative methods. Radiculopathy is nervous root injury caused by space obstruction, caused by intervertebral disc her- niation, spondylosis or osteophytes. This bone and ligament compression triggers pain irradiated to upper and lower limbs, weakness, paresthesia and sensation of edema ${ }^{48}$

The objectives of the conservative treatment are movement amplitude gain, strengthening, coordination and balance. Manual therapy is used in radiculopathies with muscle energy techniques, mobilization without thrust, manipulation; cold therapy and traction modalities, therapeutic massage, medication and cervical collar ${ }^{48,49}$. Manual therapy and exercises present high scientific evidence for short term pain relief, moderate evidence for improved quality of life and low scientific evidence for long term effect in decreasing pain and incapacity or function gain ${ }^{50}$.

A randomized study with 42 cervical radiculopathy patients has compared the effect of mechanical cervical traction to manual cervical traction, both associated to segmental mobilization and therapeutic exercises. Frequency of intervention was three weekly sessions for six weeks. At treatment completion, both groups had improved pain and incapacity, without significant difference between groups, although there is a clinical trend toward better effect of mechanical as compared to manual traction ${ }^{51}$.

A systematic review estimates that $57 \%$ of patients improve when submitted to manual therapy or neural mobilization and $46 \%$ when submitted to muscle energy technique. This systematic review has included just four studies. Authors emphasize the lack of randomized studies, control groups and comparison among therapeutic resources. Another important limitation of the studies on manual therapy is the lack of description of the techniques used in tested protocols ${ }^{48}$.

Regardless of treatment of cervical radiculopathies being exclusively conservative or associated to surgery, prevention of recurrences and functional recovery involve muscle training, medication, cervical traction, manual therapy or cervical collar. Exercises are becoming popular due to their promising effects in function and mobility gain. Muscle training involves strengthening, in general by isometric exercises of deep cervical flexor muscles, shoulders retraction and scapular muscles. Stretching exercises especially address neck, shoulder girdle and chest.

Some studies combine aerobic exercises to this analytical training. The effectiveness of this modality may be identified by body function and structures gain, by increased social participation and levels of activity and by improved personal factors, such as mood and satisfaction ${ }^{52}$.

Clinicians and researchers discuss the level of evidence of such therapeutic modalities. On the one hand, researchers aim at identifying the therapeutic effect of each technique independently. On the other hand, clinicians advocate the combination of techniques and manifest perceptions of effect enhancement by interaction among them. There are studies investigating combined treatments and which have confirmed clinicians' perceptions, however without assessing the level of efficacy of each modality and their interactions. Improved functionality and pain relief are significant findings of treatment with combined therapeutic modalities ${ }^{53}$.

Most accepted mechanism for lumbar radiculopathies is propulsion of nucleus pulposus with breakage of intervertebral disc fibrous ring, causing immune irritation in adjacent nervous roots. This change in intervertebral disc induces biomechanical imbalance in lumbar spine and promotes neurologic deficit associated to the involvement of the nervous root, impairing joint alignment of lumbar spine vertebrae. Physiotherapists tend to consider this change in vertebral alignment as a key-point for the pathologic mechanics of radiculopathies. A reaction of joint protection inducing peripheral nerve irritation, or vice-versa, is described.

Manipulations (therapeutic maneuvers in high velocity and low movement amplitude) and segmental mobilizations (low velocity maneuvers) are popular for promoting biomechanical adjustment with movements directed to recovery of lumbar spine movement amplitude and nervous root decompression. In parallel, they foster discussions on the challenge of such techniques to assure safety and efficacy of acute radiculopathy treatment, because there would be risk of injury with joint involvement in the intervertebral disc ${ }^{55}$. Meta-analyses and systematic reviews highlight the low risk and equivalent efficacy to conventional treatments such as analgesics, physiotherapy, exercises and posture/spine schools ${ }^{56,57}$.

Physical exercise is also part of the list of therapeutic options for radiculopathies. Regular exercises of moderate intensity tend to favor sensory motor functions and the regeneration potential of injured axons. In summary, results of animal model studies propose this effect of exercise by increased neurotrophin levels, neural activity recoding, peripheral sensory reorganization, 
supraspinal neuronal excitability change and cortical sensory projections ${ }^{58}$. For example, a study by Cobianchi et al. ${ }^{59}$ has compared two treadmill running protocols in mice after chronic sciatic nerve constriction injury. Brief protocol of exercises ( $1 \mathrm{~h}$ per day in the 5 days following experimental nervous injury) has decreased NP symptoms (decreased allodynia, decreased microglia and astrocytes expression). A brief running protocol has promoted acceleration of sciatic nerve regeneration process. A different animal model study with treadmill walking protocol in low intensity complements the mechanism of exercise-induced analgesia by treadmill exercise with serotoninergic involvement, in addition to decreasing pro-inflammatory cytokines ${ }^{60}$.

Although evidences of physical exercise effect in animal models being attractive, similar studies in humans are scarce in the literature ${ }^{61}$. Some techniques aim at rebalancing body structures by neural and adjacent tissues mobilization (neural mobilization), however still showing low therapeutic effect to treat peripheral nerve injury or compression ${ }^{62}$. High frequency rTMS was better than anodal CCTS or simulated treatments in decreasing pain secondary to lumbar radiculopathy ${ }^{63}$.

Cervical collars are in general prescribed to decrease foramen compression and, as a consequence, nervous roots inflammation by means of limiting vertebral movement amplitude. Kuijper et al. ${ }^{64}$ have evaluated cervical collor or physiotherapy versus expectant therapy in patients with recent cervical radiculopathy and have concluded that, during the acute phase, both approaches promote short-term relief. Zarghooni et al. ${ }^{65}$ have reviewed the use and indication of cervical and lumbar orthoses to treat acute and chronic spinal diseases highlighting the lack of high quality studies and observing that with regard to lumbar vests there are no scientific evidences offering support to their therapeutic use, as well as those proving their ineffectiveness.

A clinical randomized and controlled study has evaluated the effect of contrast baths in the pre and postoperative treatment of carpal tunnel syndrome, having hand volume as studied variable. Although not having evaluated pain in studied groups, authors concluded that contrast baths were not effective to decrease hand edema, and discuss the lack of randomized trials to support the clinical use of this therapeutic technique, including standardized protocols ${ }^{66}$.

\section{PHYSICAL REHABILITATION IN SPECIAL CASES OF NEUROPA- THIC PAIHN}

\section{Burned patients}

Generalized neuropathy after burn injuries is a common morbidity, however of difficult diagnosis and handling of nervous compression syndromes after thermal or electric burns, however poorly documented for chemical burns. Of early manifestation in the first months following burn injury, to late manifestations more than four years after injury, it requires systematic evaluations as well as early NP diagnosis in burned patients ${ }^{67}$. It affects between $2 \%$ and $84 \%$ of patients and the cause is difficult to evaluate due to the complex metabolic nature in burned patients, to subsequent use of neurotic antibiotics and other numerous iatrogenic neuropathy causes.

Peripheral neuropathy is one of the most common neuromuscular complications in burned patients and probably the less diagnosed and inadequately treated ${ }^{68,69}$. Nervous compression is manifested by electric and thermal shock sensations which are described as pain worsening with signs of allodynia, hyperalgesia and itching. Males tend to have more neuropathy signs as compared to females, and patients with body surface burns above $10 \%$ have higher prevalence of neuropathic pain ${ }^{70}$. Surgical intervention for nerve decompression is required for most patients ${ }^{67}$.

Nerve decompression is considered an effective procedure promoting motor and sensory dysfunction improvement after late burn injury in limbs, although some patients remain with paresthesia and "drop foot", morbidities affecting a small number of patients ${ }^{71}$.

In an observational longitudinal study with burned patients, $46 \%$ of cases had carpal tunnel nervous compression ${ }^{67}$. Hands integrity is critical for daily activities with special attention to their rehabilitation by the importance of highly affected precision and functionality by the risk of injury. Contractures are most common complications identified by physiotherapists. Functional, post-burn injury treatment concentrates in the use of splints, long physiotherapy sessions to prevent edema, contractures and to maintain or improve movement amplitude, recover function, prevent keloids, regain muscle strength and esthetic and functional results.
In a report of four years of experience with rehabilitation after burn injuries, these gains are highlighted, however authors do not address NP treatment in burned patients $s^{72}$. In general, there is a gap in burned patients' care on part of professionals acting on function and motor autonomy gain. There are long descriptions and discussions on movement amplitude gain and contractures prevention ${ }^{73}$ without addressing the frequent morbidity of peripheral neuropathy. The reflection on the subject is important since these are professionals with daily contact with patients, whose maneuvers for mobility gain in general induce pain and they should be alert for late, post-burn injury nervous compression signs.

Severe burn injuries may produce scars with excruciating pain difficult to handle due to poor response to conventional treatments. In search of therapeutic alternatives, Cuignet et al. ${ }^{7,4}$, in Belgium, have applied an analgesia protocol with electroacupuncture in 32 patients with signs and symptoms of NP and pathological burn scars, without favorable response to previous treatments. Following the protocol and according to Traditional Chinese Medicine (TCM), 30-minute sessions three times a week, they have observed decrease in pain intensity, relevant only for patients with localized burn injuries, without significant effect on patients with generalized hyperalgesia. Somatosensory rehabilitation in post-burn injury NP patients has different effects, in some cases improving sensitivity and in others not ${ }^{75}$. Somatosensory rehabilitation aims at addressing hypoesthesic zones, based on somatosensory system neuroplasticity concepts and proposes that mechanical allodynia masks sensitivity and could be initially treated by hypoesthesic areas.

A protocol has tested 17 burned patients for discrimination of touch, textures perception and vibratory stimulus only in hypoesthesic regions, tested with monofilaments. Six patients had no longer allodynia after treatment of their hypoesthesic regions. However, study results have not shown significant effect of the protocol in this sample. Further studies should be carried out to answer to several methodological gaps of this study.

A different potential approach to treat burned patients with NP would be rTMS. Aiming at evaluating neuroplastic changes associated to chronic NP in this population, Portilla et al. ${ }^{76}$ have carried out a double-blind study of a session with sham excitability and primary motor cortex anode, contralateral to worst body pain symptom. However, this first study has not shown clinical changes in a single session. As well as previous studies, there are early evidences with this case series that, similar to chronic pain patients, burned patients have central mechanism with decreased cortical sensitivity and could benefit from rTMS.

\section{Phantom limb pain}

Referred severe pain in amputated body segment by surgical procedure, be it by disease, such as in diabetic neuropathy, by trauma or electric shock, it is estimated that this complaint reaches $50 \%$ to $90 \%$ of amputees $^{77}$ and that only $5 \%$ to $10 \%$ of them complain of severe phantom limb pain ${ }^{78}$. The prevalence of phantom limb pain varies according to characteristics of the population and pre, peri and post-amputation anesthetic procedures ${ }^{79}$.

Phantom limb pain phenomenon was described in the $16^{\text {th }}$ Century by Ambroise Paré and its mechanism is still not clear. Since its description, several hypotheses were proposed, since peripheral causes, such as neuroma, increased peripheral axon excitability, trigger-points; spinal cord mechanisms, spinal cord reorganization after peripheral nerve injury changes; to CNS system changes.

Based on technological imaging diagnosis advances, recent studies have shown primary somatosensory cortex reorganization after amputation, being these findings correlated to phantom limb pain magnitude ${ }^{80}$. This reorganization is due to maladaptive changes in different neuromatrix levels and may be associated to poor body representation in patients by the lack of afferent signal due to limb or segment amputation ${ }^{81}$. Another curiosity is that, in addition to decreased gray matter in motor cortex of amputees, there is increased gray matter in visual field regions, suggesting the hypothesis of compensation of sensory motor loss with visual adaptation mechanisms to maintain body function and integrity ${ }^{82}$.

Therapeutic modalities for phantom limb pain management lack scientific evidences and are clinically classified as unsatisfactory. Patients self-evaluate their therapeutic experience and establish a success rate to treatments. Pharmacological approaches vary from 67 to $21 \%$, for opioids and steroids, respectively. Interventionist treatments vary from $58 \%$ for subarachnoid opioid pump to up to $20 \%$ for contralateral anesthesia.

Among non-pharmacological options, relaxation is associated to $41 \%$ suc- 
cess, TENS to $28 \%$, and hypnosis with the lowest success rate, $19 \%{ }^{77}$. New therapeutic approaches based on neurophysiologic concepts use discriminative sensory training ${ }^{83}$, virtual mental exercises ${ }^{84}$ and mirror image projection $^{85}$ and renew patients and health professionals hope.

Mirror therapy for phantom limb pain patients stresses the importance of establishing the illusion of the phantom limb in the mirror projection of the intact limb. Those bilaterally amputated cannot be submitted to this therapeutic option. Treatment effect depends on the virtual sensation of "having back the amputated limb" in the mirror projection.

While patients look at the mirror and visualize their phantom segment and by means of motor commands for both limbs they perform symmetric movements and notice that their phantom limb "obeys" to their commands, this allows the reconstruction of the body image and in some cases partial pain decrease ${ }^{85}$. Therapy consists in developing voluntary movements ability of the phantom limb and several protocols are described, from light to complex movements, performed slowly or rapidly, association of tactile stimuli to movement, supervised or not exercises.

Patients are oriented to stop the activity in case of adverse effects, such as dizziness and emotional discomfort by visual sensation of the phantom limb, in addition to pain intensity increase. Some patients have described cramps when "performing voluntary phantom limb movement" (confirmed by mirror projection). Due to the risk of worsening pain, some physiotherapists prefer evolving to voluntary movements only after reaching painless movement amplitude in the phantom limb mirror projection ${ }^{86,87}$.

This phenomenon has also been described in CRPS patients ${ }^{88}$. In comparing the effect of mirror therapy and TENS, Tilak et al. ${ }^{89}$ have shown that both therapies induce significant pain intensity decrease, without statistical or clinical difference between both methods applied during four weeks. Mental image projection activates sensory and motor cortex and its regular practice could promote enough stimuli to reorganize cortical neurons and potentially reorganize phantom pain ${ }^{84,90}$. So, visualization and observation of movements are used with phantom segments, associated or not to meditation and relaxation. At the end of six weeks, with weekly frequency, with relaxation, body perception and imagined movements, Maclver et al. ${ }^{84}$ have observed constant pain intensity decrease correlated to cortical reorganization by means of functional magnetic resonance images. Equivalent methods are used in patients with bilateral lower limbs amputation.

Tung et al. ${ }^{91}$ have compared the effect of observing and mentally visualizing the movement of amputated segments. Patients who visually observed the movement had pain intensity decrease, as opposed to the other group, who had no difference. These are promising results because they stress the importance of motor-visual stimuli as facilitators of this cortical reorganization. The combination of therapeutic modalities with progressive muscle relaxation training, mental imagery and exercises for amputated limb, provides significant and clinical pain intensity improvement as compared to the control group at the end of four weeks with sessions twice a week ${ }^{92}$.

\section{Complex regional pain syndrome}

Similar to phantom pain approaches, mirror therapy, mental imagery and discriminative sensory training strategies are applied to patients with CRPS. Effects are questionable, varying among studies, however promising. As opposed to these innovative approaches to treat difficult to handle pain, clinical practice uses passive excruciating pain-inducing mobilizations and contrast baths. Both techniques are questionable when compared to plasticity and metaplasticity mechanisms of pain nociceptive pathways. Spatial and temporal sum of pain would be a risk factor of these mechanisms, making clinical presentation even more complex and difficult to handle.

Although questionable due to their neurophysiologic effects, $70 \%$ of professionals report using this approach in their clinical practice ${ }^{93}$. Contrast baths are described as therapeutic modality where two baths, warm and cold, are alternated, being classically used to treat extremities due to the easiness of immerging such segments ${ }^{94}$.

Although being described as alternatives to treat neuropathic pain, rheumathoid hands and diabetic feet, there are no scientific evidences supporting their clinical use. Hypothetically, their effects are based on vasodilation and vasoconstriction provoked by alternating temperature, where the goal is to mimic voluntary muscle contraction, to decrease edema, stiffness and, as a consequence, pain. Risks of this modality are recognized in patients with sensitivity loss or alteration, such as in diabetic neuropathy, however this popularization of risks does not seem to be largely applied in the clinical ap- proach of CRPS patients.

Few studies have evaluated primary motor cortex modulation with noninvasive brain stimulation techniques to treat CRPS. Pleger et al..$^{95}$ have shown a transient effect during repetitive EMT in this condition. Picarelly et al. ${ }^{96}$ have used high frequency transcranial magnetic stimulation applied to this region in CRPS type I patients and have shown pain decrease during a period of 10 consecutive sessions, with improvement in affective pain components. Peripheral stimulation with surface electrodes (TENS) seems to be more effective when associated to exercises ${ }^{97}$. However, physical treatments, including exercises, mental simulation of movements (motor imagery), mirror therapy, manual lymphatic drainage, sensory discrimination training, stellate ganglion block with low intensity ultrasound or the use of pulsed electromagnetic fields have not shown clinically significant effects on these patients $^{98}$.

\section{CONCLUSION}

NP theories and mechanisms complement each other. Opting for just one hypothesis induces health professionals and researchers to lose action potential to reverse clinical presentation or provide relief. There are several therapeutic options to treat central and peripheral neuropathic pain. One should stress old approaches which remain with good level of evidence such as TENS. Other old methods are no longer used in research, but persist in the clinical practice, such as contrast baths.

In addition to questionable neurological and/or physiological effect, this modality poses a potential risk in cases of sensitivity deficit, that is, especially in the NP population. As with chronic pain, there is a trend to improve active approaches, those requiring patients' physical and mental effort, such as: exercises, imagery, tactile discrimination and mirror therapy.

Technological advances, such as rTMS and CCTS currents, also gain space in the therapeutic approach of this population although needing further studies. Rehabilitation can and should be included as adjuvant to treat NP patients. Rehabilitation provides further autonomy and functionality to daily lives of these patients and these are, in some cases, patients' motivational objectives, being above pain relief.

\section{REFERENCES}

1. Langley PC, Van Litsenburg C, Cappelleri JC, Carroll D. The burden associated with neuropathic pain in Western Europe. J Med Econ. 2013;16(1):85-95.

2. Iftikhar M, Hussain A, Rizvi A. Frequency of peripheral neuropathy in patients with diabetes mellitus. J Ayub Med Coll Abbottabad. 2014;26(4):584-6.

3. Hadley GR, Gayle JA, Ripoll J, Jones MR, Argoff CE, Kaye RJ, et al. Post-herpetic neuralgia: a review. Curr Pain Headache Rep. 2016;20(3):17. Erratun in Curr Pain Headache Rep. 2016;20(4):28 Garcia JB, Rodrigues DP, Leite DR, do Nascimento Câmara SN, da Silva Martins S, de Moraes EB. Clinical evaluation of the post-laminectomy syndrome in public hospitals in the city of Sáo Luís, Brazil. BMC Res Notes. 2015;8:451.

5. Derakhshanrad N, Yekaninejad MS, Vosoughi F, Sadeghi Fazel F, Saberi H. Epidemiological study of traumatic spinal cord injuries: experience from a specialized spine center in Iran. Spinal Cord. 2016 doi: 10.1038/sc.2016.10. [Epub ahead of print].

6. National Institute for Health and Care Excellence. Neuropathic pain in adults: pharmacological management in non-specialist settings. Clinical guideline, 20 November 2013. nice.org.uk/guidance/cg173. gement in non-specialist settings. Clinical guideline, 20 November 2013 . nice.org.uk/guidance/cgl73.
Finnerup NB, Attal N. Pharmacotherapy of neuropathic pain: time to rewrite the rulebook? Pain Manag. 2016;6(1):1-3.

8. GMMMG Greater Manchester Medicines Management Group. Neuropathic Pain Guideline March 2014. http://gmmmg.nhs.uk/html/guidance.html (Abril 2016)

9. Multidisciplinary Association of spinal Cord Injury Professionals. Guidelines for the Management of Neuropathic Pain in Adults following Spinal Cord Injury, $2^{\text {nd }}$ ed. 2008. http://www.mascip.co.uk/ best-practice/mascip-best-practice/ (abril/2016)

10. Dobson JL, McMillan J, Li L. Benefits of exercise intervention in reducing neuropathic pain. Front Cell Neurosci. 2014;8:102

11. Barbosa JH, Oliveira SL, Seara LT. [The role of advanced glycation end-products (AGEs) in the development of vascular diabetic complications]. Arq Bras Endocrinol Metabol. 2008;52(6):940-50. Portuguese.

12. Clark RL, Bowling FL, Jepson F, Rajbhandari S. Phantom limb pain after amputation in diabetic patients does not differ from that after amputation in nondiabetic patients. Pain. 2013;154(5):729-32. Yang Z, Scott CA, Mao C, Tang J, Farmer AJ. Resistance exercise versus aerobic exercise for type 2 diabetes: a systematic review and meta-analysis Sports Med. 2014;44(4):487-99.

14. Kluding PM, Pasnoor M, Singh R, Jernigan S, Farmer K, Rucker J, et al. The effect of exercise on neuropathic symptoms, nerve function, and cutaneous innervation in people with diabetic peripheral neuropathy. J Diabetes Complications. 2012;26(5):424-9.

15. Yoo M, D'Silva LJ, Martin K, Sharma NK, Pasnoor M, LeMaster JW, et al. Pilot study of exerciYoo M, D'Silva LJ, Martin K, Sharma NK, Pasnoor M, LeMaster JW, et al. Pilot st
se therapy on painful diabetic peripheral neuropathy. Pain Med. 2015;16(8):1482-9.

16. Brod M, Pohlman B, Blum SI, Ramasamy A, Carson R. Burden of Illness of diabetic peripheral neuropathic pain: a qualitative study. Patient. 2015;8(4):339-48.

17. Sullivan M, Ballantyne JC. Must we reduce pain intensity to treat chronic pain? Pain. 2016;157(1):65-9

18. Kluding PM, Pasnoor M, Singh R, D'Silva LJ, Yoo M, Billinger SA, et al. Safety of aerobic exercise in people with diabetic peripheral neuropathy: single-group clinical trial. Phys Ther. 2015;95(2):223-34. Kessler NJ, Hong J. Whole body vibration therapy for painful diabetic peripheral neuropathy: pilot study. J Bodyw Mov Ther. 2013;17(4):518-22.

20. Kord Yoosefinejad A, Shadmehr A, Olyaei G, Talebian S, Bagheri H. The effectiveness of a single session of Whole-Body Vibration in improving the balance and the strength in type 2 diabetic patients with mild 
to moderate degree of peripheral neuropathy: a pilot study. J Bodyw Mov Ther. 2014;18(1):82-6.

21. Akyuz G, Kenis O. Physical therapy modalities and rehabilitation techniques in the management of neuropathic pain. Am J Phys Med Rehabil. 2014;93(3):253-9

22. Jin DM, Xu Y, Geng DF, Yan TB. Effect of transcutaneous electrical nerve stimulation on symptomatic diabetic peripheral neuropathy: a meta-analysis of randomized controlled trials. Diabetes Res Clin Pract. 2010;89(1):10-5

23. Mima T, Oga T, Rothwell J, Satow T, Yamamoto J, Toma K, et al. Short-term high frequency transcutaneous electrical nerve stimulation decreases human motor cortex excitability. Neurosci Lett. 2004;355(1-2):85-8.

24. Kobayashi M, Pascual-Leone A. Transcranial magnetic stimulation in neurology. Lancet Neurol. 2003;2(3):145-56.

25. Fregni F, Freedman S, Pascual-Leone A. Recent advances in the treatment of chronic pain with non-invasive brain stimulation techniques. Lancet Neurol. 2007;6(2):188-91.

26. Jensen M, Hakimian S, Sherlin LH, Fregni F. New insights into neuromodulatory approaches for the treatment of pain. J Pain. 2008;9(3):193-9

27. Kim YJ, Ku J, Kim HJ, IM DJ, Lee HS, Han KA, Kang YJ. Randomized, sham controlled trial of transcranial direct current stimulation for painful diabetic polyneuropathy. Ann Rehabil Med. 2013;37(6):766-76.

28. Mohomad AS, Mohammad R, Chusid E, Trepal M, Battaglia F. Severe chronic heel pain in a diabetic patient with plantar fasciitis successfully treated through transcranial direct current stimulation. J Am Podiatr Med Assoc. 2015;105(2):173-6.

29. Onesti E, Gabriele M, Cambieri C, Ceccanti M, Raccah R, Di Stefano G, et al. H-coil repetitive transcranial magnetic stimulation for pain relief in patients with diabetic neuropathy. Eur J Pain. 2013;17(9):1347-56

30. Fregni F, Boggio PS, Lima MC, Ferreira MJ, Wagner T, Rigonatti SP, et al. A sham-controlled, phase II trial of transcranial direct current stimulation for the treatment of central pain in traumatic spinal cord injury. Pain. 2006;122(1-2):197-209.

31. Boldt I, Eriks-Hoogland I, Brinkhof MW, de Bie R, Joggi D, von Elm E. Non-pharmacological interventions for chronic pain in people with spinal cord injury. Cochrane Database Syst Rev. 2014;11:CD009177.

32. Mehta S, McIntyre A, Guy S, Teasell RW, Loh E. Effectiveness of transcranial direct current stimulation for the management of neuropathic pain after spinal cord injury: a meta-analysis. Spinal Cord. 2015;53(11):780-5.

33. Mori F, Codecà C, Kusayanagi H, Monteleone F, Buttari F, Fiore S, et al. Effects of anodal transcranial direct current stimulation on chronic neuropathic pain in patients with multiple sclerosis. J Pain. 2010;11(5):436-42.

34. Yilmaz B, Kesikburun S, Yasar E, Tan AK. The effect of repetitive transcranial magnetic stimulation on refractory neuropathic pain in spinal cord injury. J Spinal Cord Med. 2014;37(4):397-400.

35. Jetté F, Côté I, Meziane HB, Mercier C. Effect of single-session repetitive transcranial magnetic stimulation applied over the hand versus leg motor area on pain after spinal cord injury. Neurorehabil Neural Repair. 2013;27(7):636-43

36. Kang BS, Shin HI, Bang MS. Effect of repetitive transcranial magnetic stimulation over the hand motor cortical area on central pain after spinal cord injury. Arch Phys Med Rehabil. 2009;90(10):1766-71.

37. Defrin R, Grunhaus L, Zamir D, Zeilig G. The effect of a series of repetitive transcranial magnetic stimulations of the motor cortex on central pain after spinal cord injury. Arch PHys Med Rehabil. 2007;88(12):1574-80.

38. Celik EC, Erhan B, Gunduz B, Lakse E. The effect of low-frequency TENS in the treatment of neuropathic pain in patients with spinal cord injury. Spinal Cord. 2013;51(4):334-7.

39. Bi X, Lv H, Chen BL, Li X, Wang XQ. Effects of transcutaneous electrical nerve stimulation on pain in patients with spinal cord injury: a randomized controlled trial. J Phys Ther Sci. 2015;27(1):23-5.
Eugene AR. Trigeminal neuralgia and radiofrequency lesioning. Brain. 2015;6(1-2):91-6.

41. Jia DZ, Li G. Bioresonance hypothesis: a new mechanism on the pathogenesis of trigeminal neuralgia. Med Hypotheses. 2010;74(3):505-7.

42. Abhinav K, Love S, Kalantzis G, Coakham HB, Patel NK. Clinicopathological review of patients with and without multiple sclerosis treated by partial sensory rhizotomy for medically refractory trigeminal neuralgia: a 12-year retrospective study. Clin Neurol Neurosurg. 2012;114(4):361-5.

43. Phan K, Rao PJ, Dexter M. Microvascular decompression for elderly patients with trigeminal neuralgia. J Clin Neurosci. 2016;29:7-14

44. Jones RD $3^{\text {rd }}$, Lawson E, Backonja M. Managing neuropathic pain. Med Clin North Am. 2016;100(1):151-67.

45. Singla S, Prabhakar V, Singla RK. Role of transcutaneous electric nerve stimulation in the management of trigeminal neuralgia. J Neurosci Rural Pract. 2011;2(2):150-2.

46. Yameen F, Shahbaz NN, Hasan Y, Fauz R, Abdullah M. Efficacy of transcutaneous electrical nerve stimulation and its different modes in patients with trigeminal neuralgia. J Pak Med Assoc. 2011;61(5):437-9.

47. Hagenacker T, Bude V, Naegel S, Holle D, Katsarava Z, Diener HC, et al. Patient-conducted anodal transcranial direct current stimulation of the motor cortex alleviates pain in trigeminal neuralgia. J Headache Pain. 2014;15:78

48. Boyles R, Toy P, Mellon J Jr, Hayes M, Hammer B. Effectiveness of manual physical therapy in the treatment of cervical radiculopathy: a systematic review. J Man Manip Ther. 2011;19(3):135-42.

49. Cleland JA, Whitman JM, Fritz JM, Palmer JA. Manual physical therapy, cervical traction, and strengthening exercises in patients with cervical radiculopathy: a case series. J Orthop Sports Phys Ther. 2005:35(12):802-11.

50. Miller J, Gross A, D'Sylva J, Burnie J, Goldsmith CH, Graham N, et al. Manual therapy and exercise for neck pain: a systematic review. Man Ther. 2010;15(4):334-54.

51. Bukhari SR, Shakil-Ur-Rehman S, Ahmad S, Naeem A. Comparison between effectiveness of Mechanical and Manual Traction combined with mobilization and exercise therapy in patients with cervical radiculopathy. Pak J Med Sci. 2016;32(1):31-4.

52. Cheng CH, Tsai LC, Chung HC, Hsu WL, Wang SF, Wang JL, et al. Exercise training for non-operative and post-operative patient with cervical radiculopathy: a literature review. J Phys Ther Sci. 2015;27(9):3011-8

53. Ragonese J. A randomized trial comparing manual physical therapy to therapeutic exercises, to a combination of therapies, for the treatment of cervical radiculopathy. Orthop Prac 2009;21(3):71-7.

54. Zhao P, Feng TY. The biomechanical significance of herniated lumbar intervertebral disk: a clinical comparison analysis of 22 multiple and 39 single segments in patients with lumbar intervertebral disk herniation. J Manipulative Physiol Ther. 1996;19(6):391-7.

55. Ernst E. Adverse effects of spinal manipulation: a systematic review. J R Soc Med. 2007;100(7):330-8.

56. Tuchin P. A replication of the study 'Adverse effects of spinal manipulation: a systematic review'. Chiropr Man Therap. 2012;20(1):30.

57. Assendelft WJ, Morton SC, Yu EI, Suttorp MJ, Shekelle PG. WITHDRAWN: Spinal manipulative therapy for low back pain. Cochrane Database Syst Rev. 2013;31;1:CD000447.

58. López-Álvarez VM, Modol L, Navarro X, Cobianchi S. Early increasing-intensity treadmill exercise reduces neuropathic pain by preventing nociceptor collateral sprouting and disruption of chloride cotransporters homeostasis after peripheral nerve injury. Pain. 2015;156(9):1812-25.

59. Cobianchi S, Marinelli S, Florenzano F, Pavone F, Luvisetto S. Short- but not long-lasting treadmill running reduces allodynia and improves functional recovery after peripheral nerve injury. Neuroscience. 2010;168(1):273-87.

60. Bobinski F, Ferreira TA, Córdova MM, Dombrowski PA, da Cunha C, Santo CC, et al. Role of brainstem serotonin in analgesia produced by low-intensity exercise on neuropathic pain after sciatic nerve injury in mice. Pain. 2015;156(12):2595-606

61. Armada-da-Silva PA, Pereira C, Amado S, Veloso AP. Role of physical exercise for improving posttraumatic nerve regeneration. Int Rev Neurobiol. 2013;109:125-49.

62. Efstathiou MA, Stefanakis M, Savva C, Giakas G. Effectiveness of neural mobilization in patients with spinal radiculopathy: a critical review J Bodyw Mov Ther. 2015;19(2):205-12.

63. Attal N, Ayache SS, Ciampi de Andrade D, Mhalla A, Baudic S, Jazat F, et al. Repetitive transcranial magnetic stimulation and transcranial direct-current stimulation in neuropathic pain due to radiculopathy: randomized sham-controlled comparative study. Pain. 2016;157(6):1224-31.

64. Kuijper B, Tans JT, Beelen A, Nollet F, de Visser M. Cervical collar or physiotherapy versus wait and see policy for recent onset cervical radiculopathy: randomised trial. BMJ. 2009;339:b3883.

65. Zarghooni K, Beyer F, Siewe J, Eysel P. The orthotic treatment of acute and chronic disease of the cervical and lumbar spine. Dtsch Arztebl Int. 2013;110(44):737-42.

66. Janssen RG, Schwartz DA, Velleman PF. A randomized controlled study of contrast baths on patients with carpal tunnel syndrome. J Hand Ther. 2009;22(3):200-7.

67. Ferguson JS, Franco J, Pollack J, Rumbolo P, Smock M. Compression neuropathy: a late finding in the post burn population: a four-year institutional review. J Burn Care Res. 2010;31(3):458-61.

68. Taman Y, Taman C, Taman B, Ustundag M, Orak M, Tasdemir N. Peripheral neuropathy after burn injury. Eur Rev Med Pharmacol Sci. 2013;17(Suppl 1):107-11.

69. Piotrowski A, Fillet AM, Perez P, Walkowiak P, Simon D, Corniere MJ, et al. Outcome of occupational electrical injuries among French electric company workers: A retrospective report of 311 cases, 1996-2005. Burns. 2014;40(3):480-8

70. Taverner T, Prince J. Acute neuropathic pain assessment in burn injured patients: a retrospective review. Wound Ostomy Continence Nurs. 2016;43(1):51-5.

71. Wu C, Calvert CT, Cairns BA, Hultman CS. Lower extremity nerve decompression in burn patients. Ann Plast Surg. 2013;70(5):563-7.

72. Rrecaj S, Hysenaj H, Martinaj M, Murtezani A, Ibrahimi-Kacuri D, Haxhiu B, et al. Outcome of physical therapy and splinting in hand burns injury. Our last four years' experience. Mater Sociomed. 2015;27(6):380-2.

73. Parry I, Painting L, Bagley A, Kawada J, Molitor F, Sen S, et al. A pilot prospective randomized contro trial comparing exercises using videogame therapy to standard. physical therapy: 6 months follow-up. J Burn Care Res. 2015;36(5):534-44

74. Cuignet $\mathrm{O}$, Pirlot A, Ortiz S, Rose T. The effects of electroacupuncture on analgesia and peripheral sensory thresholds in patients with burn scar pain. Burns. 2015;41(6):1298-305.

75. Nedelec B, Calva V, Chouinard A, Couture MA, Godbout E, de Oliveira A, et al. Somatosensory rehabilitation for neuropathic pain in burn survivors: a case series. J Burn Care Res. 2016;37(1):e37-46.

76. Portilla AS, Bravo GL, Miraval FK, Villamar MF, Schneider JC, Ryan CM, et al. A feasibility study assessing cortical plasticity in chronic neuropathic pain following burn injury. J Burn Care Res. 2013;34(1):e48-52.

77. Kern U, Busch V, Müller R, Kohl M, Birklein F. Phantom limb pain in daily practice--still a lot of work to do! Pain Med. 2012;13(12):1611-26

78. Nikolajsen L. Postamputation pain: studies on mechanisms. Dan Med J. 2012;59(10):B4527.

79. Hsu E, Cohen SP. Postamputation pain: epidemiology, mechanisms, and treatment. J Pain Res. 2013:6:121-36.

80. Flor H, Elbert T, Knecht S, Wienbruch C, Pantev C, Birbaumer N, et al. Phantom-limb pain as a perceptual correlate of cortical reorganization following arm amputation. Nature. 1995;375(6531):482-4

81. Giummarra MJ, Moseley GL. Phantom limb pain and bodily awareness: current concepts and future directions. Curr Opin Anaesthesiol. 2011;24(5):524-31.

82. Preissler S, Feiler J, Dietrich C, Hofmann GO, Miltner WH, Weiss T. Gray matter changes following limb amputation with high and low intensities of phantom limb pain. Cereb Cortex. 2013;23(5):1038-48.

83. Flor H, Denke C, Schaefer M, Grüsser S. Effect of sensory discrimination training on cortical reorganisation and phantom limb pain. Lancet. 2001;357(9270):1763-4.

84. Maclver K, Lloyd DM, Kelly S, Roberts N, Nurmikko T. Phantom limb pain, cortical reorganization and the therapeutic effect of mental imagery. Brain. 2008;131(Pt 8):2181-91.

85. Ramachandran VS, Altschuler EL. The use of visual feedback, in particular mirror visual feedback, in restoring brain function. Brain. 2009:132(Pt 7):1693-710.

86. McCabe C. Mirror visual feedback therapy. A practical approach. J Hand Ther. 2011;24(2):170-8.

87. Rothgangel A, Braun S, de Witte L, Beurskens A, Smeets R. Development of a clinical framework for mirror therapy in patients with phantom limb pain: an evidence-based practice approach. Pain Pract. 2016;16(4):422-34.

88. Moseley GL, Zalucki N, Birklein F, Marinus J, van Hilten JJ, Luomajoki H. Thinking about movement hurts: the effect of motor imagery on pain and swelling in people with chronic arm pain. Arthritis Rheum. 2008;59(5):623-31.

89. Tilak M, Isaac SA, Fletcher J, Vasanthan LT, Subbaiah RS, Babu A, et al. Mirror therapy and transcutaneous electrical nerve stimulation for management of phantom limb pain in amputees - a single blinded randomized controlled trial. Physiother Res Int. 2015;21(2):109-15.

90. Flor H, Nikolajsen L, Staehelin Jensen T. Phantom limb pain: a case of maladaptive CNS plasticity? Nat Rev Neurosci. 2006;7(11):873-81

91. Tung ML, Murphy IC, Griffin SC, Alphonso AL, Hussey-Anderson L, Hughes KE, et al. Observation of limb movements reduces phantom limb pain in bilateral amputees Ann Clin Transl Neurol. 2014;1(9):633-8.

92. Brunelli S, Morone G, Iosa M, Ciotti C, De Giorgi R, Foti C, et al. Efficacy of progressive muscle relaxation, mental imagery, and phantom exercise training on phantom limb: a randomized controlled trial. Arch Phys Med Rehabil. 2015;96(2):181-7.

93. Breger Stanton D, Lazaro R, Macdermid JC. A systemic review of the effectiveness of contrast baths. J Hand Ther, 2009;22(1):57-70.

94. Basford, JF. Agentes Físicos. In: DeLisa JA, Gans BM. Tratado de Medicina Física e Reabilitaçáo, $3^{\mathrm{a}}$ ed. São Paulo: Editora Manole; 2002. 510p.

95. Pleger B, Janssen F, Schwenkreis P, Völker B, Maier C, Tegenthoff M. Repetitive Transcranial magnetic stimulation of the motor cortex attenuates pain perception in complex regional pain syndrome type I. Neurosci Lett. 2004;356(2):87-90.

96. Picareli H, Teixeira MJ, de Andrade DC, Myczkowski ML, Luvisotto TB, Yeng LT, et al. Repetitive Transcranial magnetic stimulation is efficacious as an add-on to pharmacological therapy in complex regional pain syndrome (CRPS) type I. J Pain. 2010;11(11):1203-10.

97. Bilgili A, Cakir T, Dogan SK, Ercalik T, Filiz MB, Toraman F The effectiveness of transcutaneous electrical nerve stimulation in the management of patients with complex regional pain syndrome: a randomized, double-blinded, placebo-controlled prospective study. J Back Musculoskeletal Rehabil. 2016;16 [Epub ahead of print].

98. Smart KM, Wand BM, O'Connell NE. Physiotherapy for pain and disability in adults with complex regional pain syndrome (CRPS) types I and II. Cochrane Database Syst Rev. 2016;2:CD010853. 